ISSN: 1130-2887 - eISSN: 2340-4396

DOI: https://doi.org/10.14201/alh.26173

\title{
LA MUJER PERUANA ENTRE DOS SIGLOS: DE VÍCTIMA DE LA VIOLENCIA A ACTIVISTA DE DERECHOS HUMANOS
} (1980-2020)

Peruvian women bridging two centuries: from victim of violence to defender of human rights (1980-2020)

\author{
Agata SERRANÒ (10 agata.serrano@cepc.es ${ }^{1}$ \\ ${ }^{1}$ Centro de Estudios Políticos y Constitucionales
}

Envío: 2021-04-05

Aceptado: 2021-10-13

First View:

Publicación: 2021-12-31

RESUMEN: Al cumplirse veinte años del conflicto armado interno que causó más de 70.000 víctimas y 20.000 desaparecidos en Perú (1980-2000), este artículo, además del impacto de la violencia sufrida, se propone examinar el papel que muchas mujeres peruanas han asumido, desde los años 80 hasta hoy, como protagonistas de una incansable búsqueda de sus familiares desaparecidos y como ejemplo cívico en su activismo para el respeto de los derechos humanos.

Palabras clave: violencia contra la mujer; desaparecidos; movimientos de derechos humanos; conflicto armado interno; Perú

ABSTRACT: Twenty years ago the internal armed conflict that cost more than 70,000 victims and 20,000 disappearances in Peru (1980-2000). In addition to the impact of the suffered violence, this article aims to examine the role that many Peruvian women have played as protagonists of a tireless search for their disappeared relatives and as civic examples in their activism for the respect of human rights from the 1980 s to the present day.

Keywords: violence against women; the disappeared; pro human rights movements; internal armed conflict; Peru 


\section{INTRODUCCIÓN}

Esta investigación se propone explorar el impacto de la violencia ejercida sobre las mujeres y sobre sus familiares por los principales actores del conflicto armado interno (CAI) y examinar el papel que ellas han asumido en la sociedad peruana desde los años 80 hasta hoy. Este trabajo, por tanto, pretende dar respuesta a las siguientes preguntas de investigación: ¿Qué impacto ha tenido la violencia del CAI peruano sobre las mujeres? ¿Cuál ha sido el papel de las mujeres peruanas durante el conflicto y el posconflicto?

Con el fin de responder a dichas preguntas, se llevó a cabo una investigación de campo en Perú, concretamente en las ciudades de Lima y Ayacucho en 2018, durante la cual se entrevistó a 7 mujeres, líderes de asociaciones que luchan para la defensa de los derechos humanos y/o familiares de víctimas desaparecidas o asesinadas durante el CAI (1980-2000). La adopción de la entrevista cualitativa en profundidad nos ha permitido comprender su realidad, obteniendo una representación general de las percepciones de las entrevistadas sobre sus vivencias durante y después del conflicto. De hecho, la técnica de la entrevista cualitativa tiene el objetivo de conocer la perspectiva del sujeto estudiado, comprender sus categorías mentales, sus interpretaciones, sus percepciones (Corbetta, 2003, pp. 343-373). Como afirma Michael Patton «la finalidad de la entrevista es entender cómo ven el mundo los sujetos estudiados, comprender su terminología y su modo de juzgar, captar la complejidad de sus percepciones y experiencias individuales» (Patton, 1990, p. 290).

La tipología de entrevista empleada fue la semiestructurada, puesto que esta modalidad favorece la expresión del/la entrevistado/a, concediendo amplia libertad al/a la entrevistador/a para abordar los temas relevantes de la investigación, que no está obligado/a a seguir un orden específico en la formulación de las preguntas. Durante las entrevistas, se ha procurado evitar preguntas directas que pudieran herir la sensibilidad de las entrevistadas o producirles una victimización secundaria, siguiendo los criterios éticos de entrevista cualitativa a sujetos vulnerables (Varona, 2015).

Si bien parte de esta investigación ha consistido en la recogida y el análisis de fuentes primarias como las entrevistas, también hemos consultado fuentes secundarias como el Informe de la CVR, artículos publicados en revistas especializadas, libros, legislación, informes institucionales y/o privados, sentencias, artículos de prensa, etc.

Por lo que se refiere a la muestra de entrevistadas, habiendo adoptado la técnica de la entrevista cualitativa, nuestro objetivo no fue el de obtener una muestra estadísticamente representativa. Por tal razón, no se usaron criterios que permitieran una cierta proporcionalidad entre el número de entrevistadas y el número total de víctimas de la violencia ni se pretendió que la muestra pudiera reproducir a un tamaño reducido las características de una determinada población estadística. Nuestro objetivo fue únicamente el de reunir una muestra variada de mujeres que habían sufrido una violación de los derechos humanos o bien personalmente o bien en su ámbito familiar para conocer su experiencia de victimización. Tal muestra fue reunida adoptando la técnica del snowball sampling, según la cual los contactos iniciales con los/ as primeros/as entrevistados/as suelen ser proporcionados por entidades locales presentes en la comunidad que posiblemente estén relacionadas con el tema de la investigación (Corbin y Strauss, 2008). En nuestro caso, estas entidades fueron algunas asociaciones y fundaciones de familiares de personas asesinadas o desaparecidas que contactamos en Lima y Ayacucho. 
Según esta técnica, usada para acercarse a colectivos especialmente difíciles de contactar, el/ la entrevistador/a accede a otros potenciales participantes gracias a los contactos sugeridos por los primeros entrevistados. Durante nuestro trabajo de campo muchas víctimas entrevistadas nos pusieron en contacto con otras que ellas mismas conocían.

Las entrevistas se analizaron con el software para el análisis cualitativo Atlas.ti 8, que nos ha permitido obtener una representación gráfica de los testimonios que presentaremos a lo largo de este artículo. Hay que precisar que los fragmentos de entrevista elegidos no pueden considerarse como una narrativa oficial de ninguna asociación o colectivo de víctimas. Asimismo, la elección de dichas participantes en lugar de otras no respondió a ninguna intención de discriminación personal o colectiva. Del mismo modo, se considera que esta investigación es un estudio preliminar que constituye el punto de partida para el planteamiento de futuros trabajos.

\section{LA VIOLENCIA CONTRA LA MUJER EN SITUACIONES DE CONFLICTO}

La violencia sexual contra las mujeres fue una de las prácticas más recurrentes en los conflictos armados durante el siglo XX (Ríos y Brocate, 2017). Entre ellas, destacan por ejemplo las violaciones sexuales producidas durante la Segunda Guerra Mundial por el ejército soviético a alrededor de 100.000 mujeres alemanas o la explotación sexual cometida por el ejército japonés en perjuicio de más de 200.000 mujeres en burdeles militares extendidos por toda Asia para elevar la moral de las tropas (Villellas et al., 2016). Igualmente, según la ONU, en Ruanda, entre 100.000 y 250.000 mujeres fueron violadas durante el genocidio de 1994; más de 60.000 mujeres fueron violadas durante la guerra civil en Sierra Leona (1991-2002); más de 40.000 en Liberia (1989-2003), y al menos 200.000 en la República Democrática del Congo desde 1998 (ONU, 2015). En la guerra de los Balcanes de los años 90, se calcula que alrededor de 40.000 mujeres y niñas musulmanas fueron violadas masivamente por las tropas serbias. En esta ocasión, con la creación del Tribunal Penal Internacional para la ex Yugoslavia (TPIY), la violencia sexual fue por primera vez considerada como crimen de lesa humanidad y crimen de guerra (Jara Gómez, 2013), tal como también se reconoció en 1999 en el Estatuto de Roma (ER) que instituyó la Corte Penal Internacional (1999), en sus artículos 7.1. letra g) y 8.2. letra b) (Lirola y Martín, 2016).

También en los conflictos armados internos de América Latina la violencia sexual contra las mujeres se manifestó de forma masiva. En el CAI de Guatemala (1962-1996) la violación sexual fue cometida contra al menos 1.500 mujeres. Aunque también se tiene constancia de que se produjeron 626 masacres con cerca de 200.000 víctimas directas, donde la violencia sexual fue el patrón utilizado por el ejército guatemalteco antes y durante dichas incursiones sangrientas (Moreyra, 2007). Según los datos de la Unidad de Víctimas del gobierno colombiano, los delitos contra la libertad y la integridad sexual constituyen, por el número de casos, el sexto tipo de violencia que sufren las mujeres, contabilizándose durante el CAI (solo desde 1985) más de 25.000 casos (Calbet, 2018).

Todas las cifras aquí presentadas lamentablemente no reflejan los datos reales, porque la violencia sexual suele ser infradenunciada y ocultada, debido principalmente a la 
estigmatización, vergüenza y miedo a represalias que las víctimas puedan sufrir. Además, si bien los móviles de tales delitos son particulares de cada caso, existe un denominador común basado en el patriarcado y los roles de género (Calbet, 2018). En tal sentido, Aguilar y Fulchiron $(2005$, p. 4) afirman que

\begin{abstract}
la violencia sexual es considerada como síntesis política de la opresión de las mujeres. Porque implica apropiación y daño. Es un hecho político que sintetiza un acto, la cosificación de la mujer y la realización extrema de la condición masculina patriarcal. Entre las formas de este tipo de violencia, la violación es el hecho supremo de la cultura patriarcal: la reiteración de la supremacía masculina y el ejercicio del derecho de posesión y uso de la mujer como objeto de placer y destrucción.
\end{abstract}

Se podría afirmar, por tanto, que la violencia sexual durante los conflictos armados es, en buena medida, utilizada como arma de guerra, como forma de control de la sociedad o humillación simbólica del enemigo (Calbet, 2018). Es considerada como arma y estrategia de guerra, puesto que tiene como objetivo afectar al mayor número posible de personas, sembrar el terror en la población, minar la moral del enemigo al mostrar la supuesta incapacidad para defender a sus mujeres y finalmente destruir el tejido social de la población (Ruta Pacífica de las Mujeres, 2013). El proceso posterior a la violencia sexual suele estar caracterizado por la marginación y la estigmatización de las mujeres que han sido víctimas de esta violencia (Mackenzie, 2010, p. 203), a las que se culpabiliza y responsabiliza injustamente de lo ocurrido, buscando generar un mecanismo de control social que permita justificar las atrocidades y mantener la impunidad de los responsables reales (Beristain et al., 1999).

\title{
III. LA MUJER COMO VÍCTIMA DE LA VIOLENCIA SEXUAL DURANTE EL CONFLICTO ARMADO INTERNO EN PERÚ (1980-2000)
}

En este epígrafe examinaremos cómo las mujeres peruanas durante el CAI, por un lado, fueron víctimas de la violencia sexual ${ }^{1} \mathrm{y}$, por otro, fueron y, lamentablemente, siguen siendo también víctimas de una violencia indirecta que radica en discriminaciones por razones de sexo, raza y clase social ${ }^{2}$. La violencia directa se enmarca en un periodo sin precedentes que el Perú vivió entre 1980 y 2000, conocido más comúnmente como «conflicto armado interno»

1. Cuando se examina la violencia contra la mujer durante el CAI peruano no se puede olvidar que entre 1996 y 2000 el gobierno de Alberto Fujimori implementó una campaña de control demográfico con el fin de reducir el número de nacimientos en los sectores más pobres de Perú. En consecuencia, más de 272.000 mujeres fueron esterilizadas mediante la ligadura de trompas (La Vanguardia, 2021). Se estima que muchas de ellas, en su gran mayoría campesinas e indígenas de escasos recursos, fueron esterilizadas contra su voluntad. Tales delitos han tardado más de 20 años en llegar a los tribunales, ya que solo a principio de 2021 ha empezado el juicio contra Alberto Fujimori y sus exministros de Sanidad, entre otros altos cargos, por lesiones graves contra 1.300 personas y la muerte de cinco personas a causa de la esterilización forzosa (El Comercio, 2021).

2. La mujer peruana en el CAI, además de víctima, en ocasiones ha sido un actor activo ante la violencia, siendo miembro de los grupos subversivos (Díaz, 2016) o de los comités de autodefensa (Boutron, 2014). 
(CAI), durante el cual se registraron más de 69.280 víctimas mortales, según una estimación de la Comisión de la Verdad y Reconciliación (CVR), creada en 2001 para esclarecer tales hechos (Degregori, 2014).

La responsabilidad de estas violaciones se atribuyó tanto a grupos terroristas como a agentes estatales. Como se puede observar en el Gráfico 2, según el Informe Final de la CVR, el $54 \%$ de las víctimas fue causado por el grupo terrorista Sendero Luminoso (SL), el $43 \%$ fue provocado por las Fuerzas Armadas y la Policía; el restante $17 \%$ fue causado por otros actores (el grupo terrorista Movimiento Revolucionario Tupac Amaru-MRTA, rondas campesinas, comunidades de autodefensa-CADS, grupos paramilitares, agentes no identificados). Dichos actores perpetraron diferentes violaciones de derechos humanos, tales como asesinatos, ejecuciones arbitrarias o extrajudiciales, secuestros, desapariciones forzadas, tratos o penas crueles, inhumanas o degradantes, entre otras (Gráfico 3).

\section{GRÁFICO 1. NÚMERO ESTIMADO DE VÍCTIMAS MORTALES POR AÑO}

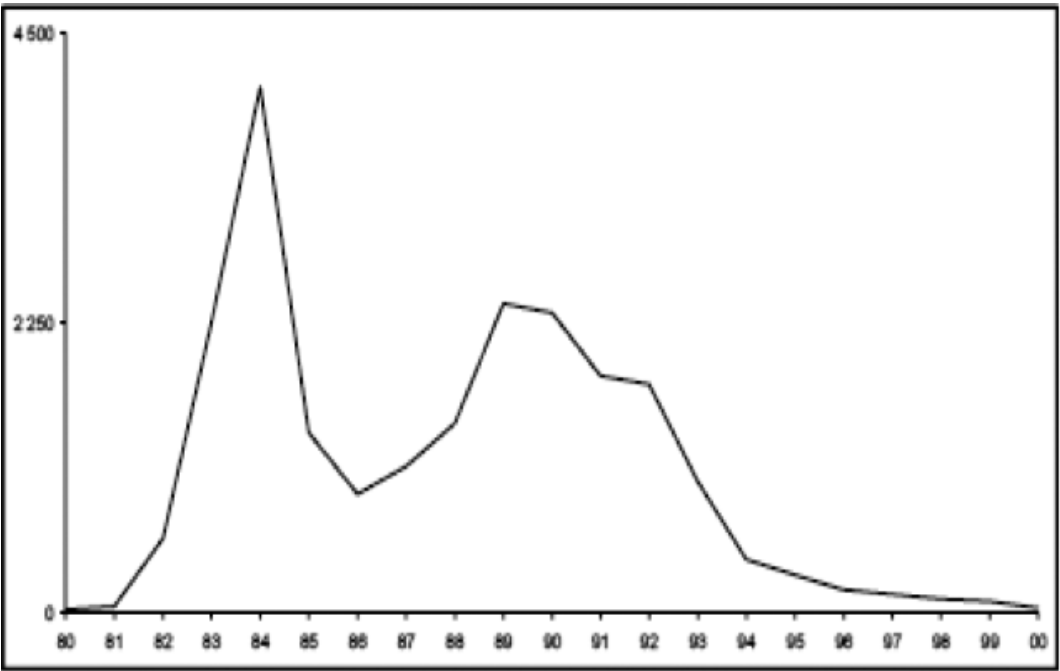

Fuente: CVR (2003f, p. 22).

Tal como se desprende del Gráfico 4, la mayor cantidad de víctimas se produjo en la región sur central del Perú, especialmente en los departamentos de Ayacucho, Junín, Huánuco, Huancavelica y Apurímac. Sin embargo, también el distrito de Lima y la selva nororiental y central se vieron severamente afectados por la violencia (CVR, 2003c). Las víctimas mortales en su mayoría fueron campesinos de las zonas más pobres y marginadas del país, pobladores quechuahablantes de las zonas rurales andinas e integrantes de diferentes comunidades indígenas de la selva. 


\section{GRÁFICO 2. PORCENTAJE ESTIMADO DEL NÚMERO DE VÍCTIMAS CAUSADAS POR RESPONSABLE}

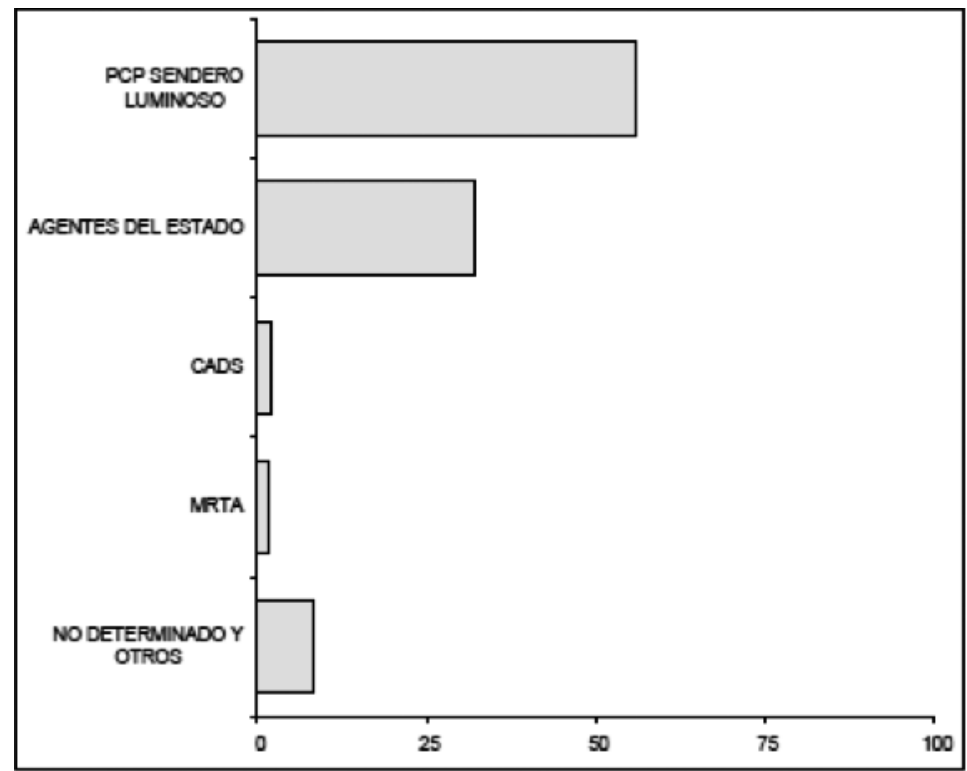

Fuente: CVR (2003f, p. 21).

En realidad, a pesar de que las mujeres representaron solo el $20 \%$ del total de las víctimas, se puede afirmar que el CAI peruano tuvo un impacto diferenciado en función del género: las mujeres, por el solo hecho de serlo, fueron víctimas de un conjunto de delitos distintos a los que sufrieron los varones (Defensoría del Pueblo, 2004, p. 43). En particular, ellas fueron víctimas de la «violencia sexual» ${ }^{3}$, es decir, insultos de carácter sexista, tocamientos, desnudos forzados, abortos forzados, uniones forzadas, esclavitud sexual, violación sexual, entre otras prácticas, cometidas tanto por agentes del Estado como por miembros de los grupos subversivos (CVR, 2003e, p. 66).

Por lo que se refiere a las violaciones sexuales, objeto de nuestro estudio, por su carácter sistemático y generalizado fueron consideradas por la CVR como un delito de lesa humanidad, tal como está contemplado por el art. 7 letra g) del ER. En concreto, la CVR enmarcó la violación sexual entre los tratos o penas crueles, inhumanas o degradantes, es decir, «las prácticas que buscan despertar en la víctima sentimientos de miedo, angustia e inferioridad

3. La violencia sexual ha sido definida por la CVR como «la realización de un acto de naturaleza sexual contra una o más personas por la fuerza o mediante la amenaza de la fuerza o mediante coacción, como la causada por el temor a la violencia, la intimidación, la detención, la opresión psicológica o el abuso de poder, contra esa(s) personas u otra persona o aprovechando un entorno de coacción o la incapacidad de esa(s) personas de dar su libre consentimiento» (CVR, 2003d, p. 264). 


\section{GRÁFICO 3. PORCENTAJE DE CRÍMENES Y VIOLACIONES A LOS DERECHOS HUMANOS Y OTROS HECHOS REPORTADOS EN CADA ACTO}

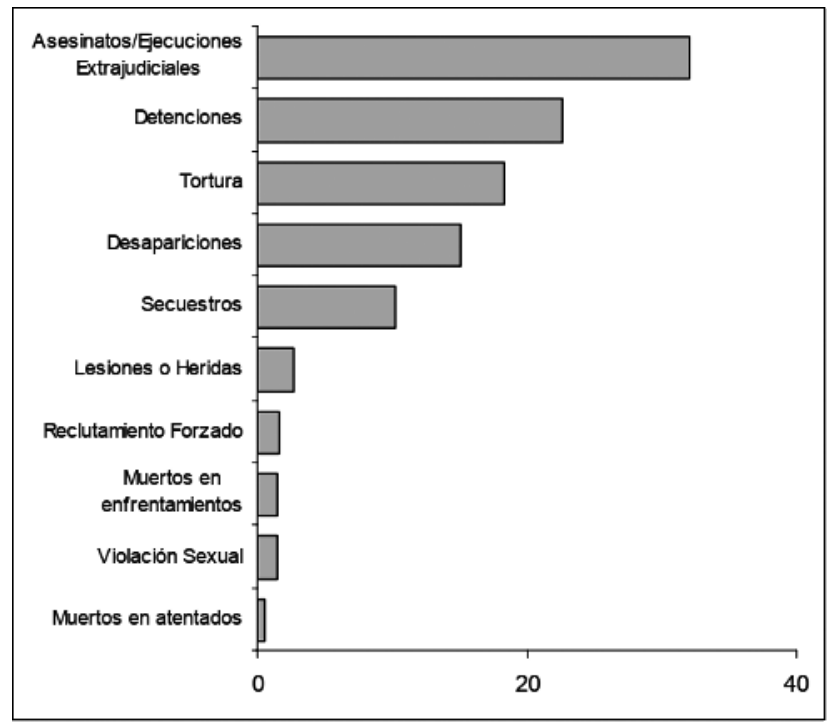

Fuente: Informe Final de la CVR (2003d), p. 274.

además de humillación y degradación; ya sea que se utilicen como medio intimidatorio, como castigo personal, para intimidar o coaccionar, como pena o por cualquier razón basada en cualquier tipo de discriminación u otro fin» (CVR, 2003b, p. 205). De hecho, además de la violencia física padecida, las víctimas de violación sexual sufren graves traumas psicológicos, generados por la humillación que la misma violación supone y el deshonor que este delito, si revelado podría causarles en el marco de su comunidad de pertenencia. Asimismo, puesto que algunas de ellas se quedan embarazadas, deben asumir solas la crianza de los hijos, la mayoría de los cuales no son reconocidos por los violadores; otras son forzadas a abortar o están sometidas a otros tipos de maltratos (COMISEDH, 2003, p. 31).

$\mathrm{Al}$ igual que la CVR, también el Sistema Interamericano de Derechos Humanos, a partir del caso María Elena Loayza vs. Perú4, se refirió a la violencia sexual dentro del marco del conflicto peruano como un trato cruel, inhumano y denigrante, que vulnera el derecho a la integridad física recogido en el art. 5 de la Convención Americana de Derechos HumanosCADH (Ríos y Brocate, 2017, p. 87).

Pero, ¿quiénes fueron los responsables de las violaciones sexuales durante el CAI peruano y quiénes fueron las víctimas? En concreto, entre las víctimas el 16,54 \% fueron hombres

4. Caso Loayza Tamayo vs. Perú (Corte Interamericana de Derechos Humanos, 1993). 


\section{GRÁFICO 4. NÚMERO ESTIMADO DE VÍCTIMAS MORTALES POR DEPARTAMENTO}

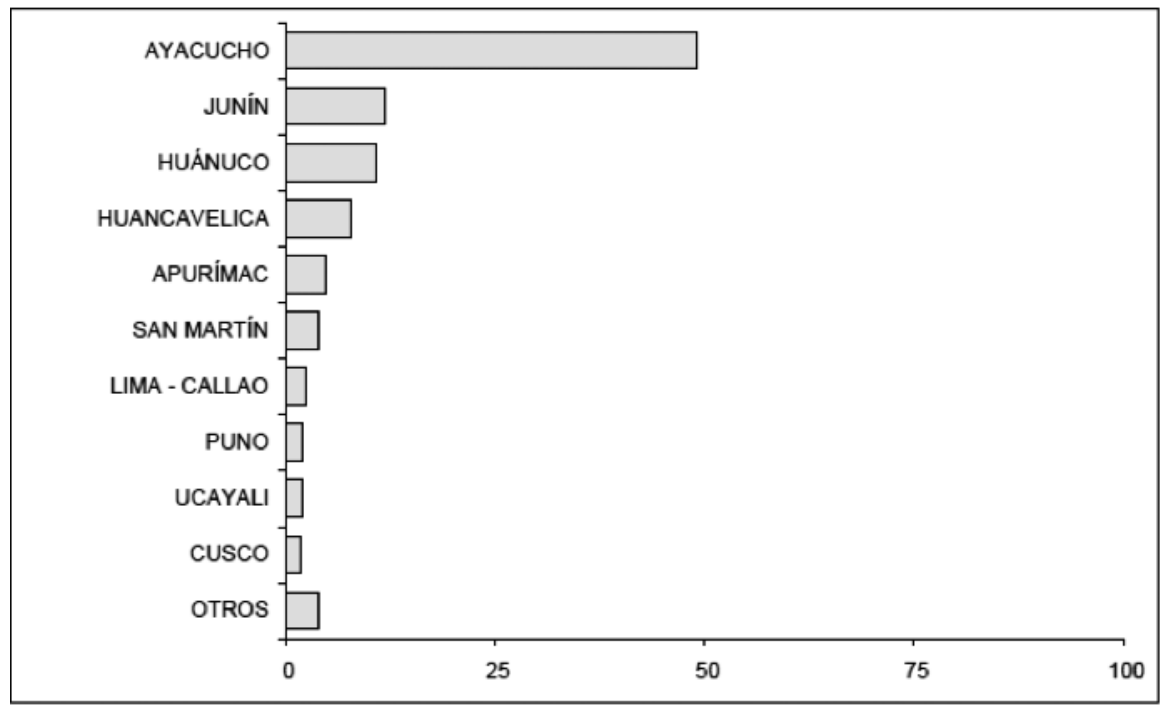

Fuente: CVR (2003f, p. 23).

y el $83,46 \%$ fueron mujeres. La mayoría de las mujeres (de las que se tiene conocimiento) tenía entre 10 y 29 años, aunque también se registraron víctimas adultas y ancianas.

Todas ellas pertenecieron a los sectores de menores recursos de la población: el $75 \%$ eran quechuahablantes, el $83 \%$ eran de origen rural, el $36 \%$ se dedicaban a actividades agrarias, el $30 \%$ eran amas de casa, especialmente de los Departamentos de Ayacucho, de Huancavelica y Apurímac, es decir, la zona de Sierra sur del Perú (CVR, 2003d, p. 281).

Con relación a los perpetradores, alrededor del $83 \%$ de los actos de violación sexual que se conocen son imputables a agentes del Estado y aproximadamente un $11 \%$ corresponden a los grupos subversivos de SL y el MRTA. Estos últimos solían emplear las violaciones sexuales como castigo, en el contexto de incursiones armadas en los poblados andinos y amazónicos, en los campamentos o «retiradas» que establecían para escapar de las fuerzas del orden, en los que se mantenían a numerosas personas en condiciones de servidumbre. Los agentes del Estado, en cambio, ejercieron las violaciones sexuales contra las mujeres consideradas sospechosas de tener vínculos con los grupos subversivos, durante los interrogatorios, las detenciones arbitrarias y/o desapariciones forzadas de personas. La violencia sexual en general fue utilizada también en muchos casos como un método de tortura para la obtención de información o confesiones autoinculpatorias (CVR, 2003d, p. 281).

Ahora bien, si observamos el Gráfico 2, a primera vista las violaciones sexuales aparecen como una práctica menos frecuente de la tortura. Sin embargo, los datos reportados no ofrecen un cuadro completo sobre la situación porque solo contabilizan casos de violación sexual de víctimas identificadas, es decir, registran solo los casos de violación sexual de 


\section{GRÁFICO 5. VIOLACIONES DE LOS DERECHOS HUMANOS REPORTADAS A LA CVR SEGÚN EL SEXO DE LA VÍCTIMA}

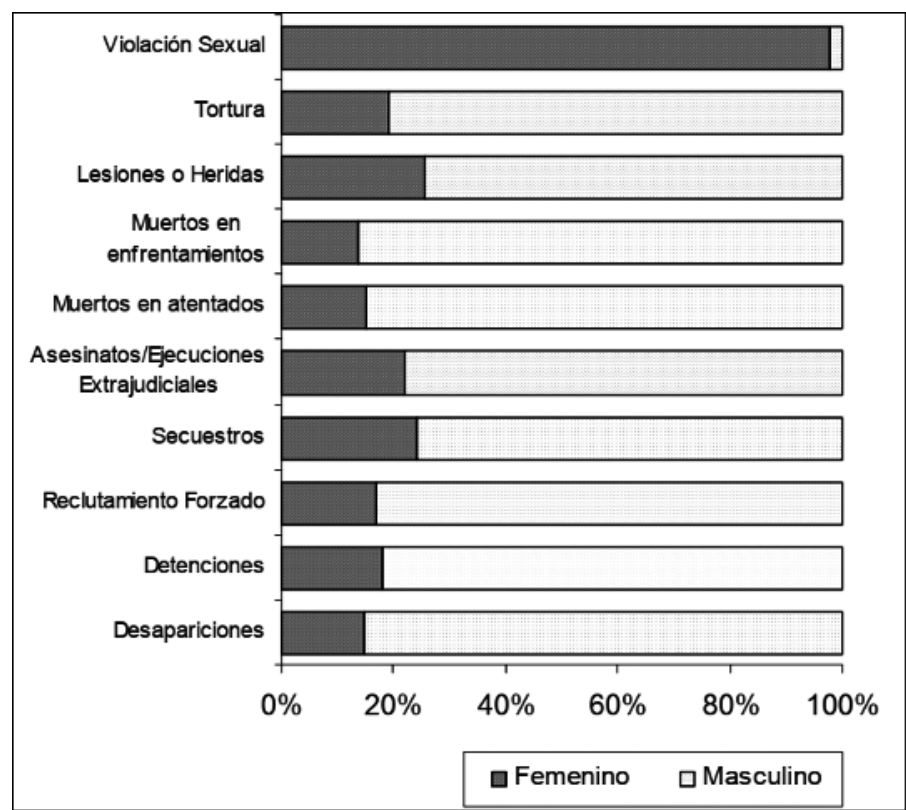

Fuente: Informe Final de la CVR (2003d), p. 273.

aquellas víctimas cuyo nombre se conoce, no recogiendo los casos en que existen referencias generales sobre los hechos (CVR, 2003d, p. 273). Por tanto, la CVR indica que existe una subrepresentación estadística de la violación sexual con respecto a las otras violaciones de los derechos humanos representadas en el Gráfico2 por al menos tres razones.

En primer lugar, por la menor disposición de las víctimas en narrar abiertamente lo ocurrido, por vergüenza, pudor o por temor a represalias. En la mayoría de los casos las mujeres violadas prefirieron guardar silencio pues sabían que no iban a encontrar una respuesta adecuada a lo sucedido ni en su familia ni en su comunidad. De hecho, muchas de las que lo revelaron recibieron ulteriores maltratos verbales, físicos y psicológicos por los esposos (o familiares), además de la acusación de que las culpables de todo habían sido ellas. Otras veces, fueron estigmatizadas, tildadas y excluidas en sus propias comunidades de pertenencia (Crisóstomo, 2015). En palabras de Ríos y Brocate (2017, p. 84), la mujer es considerada como propiedad del hombre y del conjunto colectivo (la comunidad): violar su cuerpo significa violentar a la comunidad. Esta concepción patriarcal de la sociedad y su consiguiente asignación rígida del rol hombre-mujer conlleva, sin duda, la revictimización de la misma mujer, la cual ante una violación sexual es repudiada por sus familias y marginada por el resto de la sociedad. 
En segundo lugar, la CVR afirmó que, en muchas ocasiones, las violaciones sexuales se llevaron a cabo en el marco de otras violaciones de derechos humanos (masacres, detenciones arbitrarias, ejecuciones arbitrarias, tortura, etc.), por lo que, en los casos en los que la víctima no lo revelara voluntariamente o no fuera evidente, este tipo de violencia pasó prácticamente inobservada.

En tercer lugar, la CVR subrayó que

durante mucho tiempo la violencia sexual fue vista como un daño colateral o un efecto secundario de los conflictos armados y no como una violación de derechos humanos, con lo cual estos hechos no sólo no han sido denunciados, sino que además se les ha visto como normales y cotidianos (CVR, 2003d, p. 275).

Por tanto, no solo las violaciones sexuales fueron ejercidas en la completa impunidad como si fueran implícitamente legítimas, sino que, tal como se puede observar en el Gráfico 5, a diferencia de otras violaciones de derechos humanos, fueron un delito especialmente practicado en contra de las mujeres, configurándose claramente como un tipo de «violencia contra la mujer» (COMISEDH, 2003).

Sin embargo, la violencia sexual contra las mujeres en Perú no parece haber surgido durante el conflicto, sino haber sido exacerbada por él. Siendo la sociedad peruana aún tradicional con roles hombre-mujer muy marcados, ya existía una violencia endémica contra la mujer, cuyas razones residían y, lamentablemente, aún residen en una tríplice discriminación por razones de sexo, de raza y de clase social. Durante el CAI, esta tríplice discriminación llegó a su auge, causando la violencia más despiadada, especialmente en contra de las mujeres históricamente percibidas como ciudadanas de clase baja: indígenas o campesinas de la sierra y la selva del Perú (Boesten y Fischer, 2012, p. 3). En este sentido, la violencia sexual precedió y supervivió al conflicto, no pudiéndola considerar solo una estrategia de guerra, porque fue normalizada y tolerada también en tiempos de paz, no considerándose ni siquiera como un delito. En la misma línea, Crisóstomo (2011, p. 5) afirma que

la violencia contra la mujer [peruana] y sobre todo contra la mujer campesina, nativa y/o indígena es parte de un proceso histórico que se sustenta en un antiguo y rígido modelo de las relaciones de dominación. [...] En tiempos de conflicto, los roles atribuidos a cada sexo se polarizan, la masculinidad tradicional alienta los comportamientos violentos, mientras que la mujer, portadora real y simbólica de una identidad social y cultural se convierte en territorio de conquista.

$\mathrm{Y}$ añade que, «por lo mismo, se afirma que la violencia sexual en las zonas rurales es un hecho que ya existía; durante la violencia política, sólo cambió el agreson» (Crisóstomo, 2011, p. 16).

Sin embargo, a pesar de la violencia directa e indirecta sufrida, tanto durante el conflicto como en el posconflicto, las mujeres peruanas han luchado sin tregua para obtener verdad, justicia y reparación, tal como examinaremos en el próximo epígrafe. 


\section{LAS MUJERES PERUANAS COMO EJEMPLO CÍVICO: EL ACTIVISMO EN DEFENSA DE LOS DERECHOS A LA VERDAD, LA JUSTICIA, LA MEMORIA Y LA REPARACIÓN}

Este epígrafe se centrará especialmente en la lucha pacífica de muchas mujeres peruanas para conseguir verdad, justicia y reparación, durante y después del conflicto, siendo protagonistas de una interminable y desgarradora búsqueda de sus familiares víctimas de la desaparición forzada y/o de ejecuciones extrajudiciales. Estos dos delitos, habiéndose llevado a cabo de forma generalizada y sistemática sobre todo en el departamento de Ayacucho, fueron considerados por la CVR como crímenes de lesa humanidad, de acuerdo con el ER en el art. 7 letra a) y letra i). Lamentablemente, ambas prácticas resultaron estar inequivocablemente interconectadas, puesto que las personas desaparecidas, en la mayoría de los casos, terminaron siendo ejecutadas arbitrariamente.

Según la Dirección General de Búsqueda de Personas Desaparecidas (DGBPD) establecida en 2016, que creó el Registro Nacional de Personas Desaparecidas y Sitios de Entierro (RENADE), las personas desaparecidas entre 1980 y 2000 ascienden a 20.329, aunque este número está lamentablemente destinado a subir. De los 20.329 desaparecidos, solo se han hallado los restos de al menos 865 personas, que fueron restituidos a sus familiares para su sepultura. Estas cifras convierten al Perú en uno de los países con más desaparecidos de América Latina (LUM, 2018). Las exhumaciones, identificación y entrega de restos de personas desaparecidas a sus familiares es todavía una tarea pendiente en el país.

Tal como se puede observar en el Gráfico 5, las víctimas mortales y desaparecidas fueron especialmente varones, llevando a que un significativo número de mujeres fueran testigos de la traumática pérdida de sus familiares y allegados. La desaparición y/o asesinato (y los demás delitos cometidos en contra de sus familiares) constituyeron para ellas un trauma personal y familiar significativo, marcando un antes y un después que nunca olvidarían (Defensoría del Pueblo, 2000). Lo demuestran los testimonios de las mujeres víctimas del terrorismo y de las violaciones de los derechos humanos cometidas por agentes del Estado que entrevistamos en Lima y Ayacucho en 2018, cuyos testimonios presentaremos a continuación.

En el Cuadro 1, las entrevistadas destacan como, después del asesinato o desaparición de su familiar, su propio proyecto de vida se vio truncado definitivamente. El asesinato o desaparición de un miembro de la familia llevó al quebrantamiento de sus sueños, costumbres, esperanzas de futuro y constituyó un cambio dramático de sus circunstancias, marcado por inseguridad, incertidumbre, zozobra y desesperación (Cuadro 1). Algunas de las entrevistadas (Cuadro 2) manifiestan cómo el dolor de la ausencia o de la pérdida se queda enquistado en sus vidas, volviendo a la luz en diferentes fases o momentos de la vida, cambiando sus rumbos y sus prioridades para siempre.

A causa de la violencia, muchas mujeres se quedaron sin esposos y, por ello, solas se tuvieron que hacer cargo de las labores del campo, de las tareas domésticas y de la crianza de los hijos. Su situación económica empeoró drásticamente, no sabiendo cómo sustentar a sus niños, muchos de los cuales tuvieron que empezar a trabajar desde muy temprana edad, no pudiendo seguir escolarizándose, o tuvieron que buscar los recursos económicos para seguir haciéndolo, a veces no sólo para ellos mismos, sino también para los hermanos menores (Cuadro 2). 


\section{CUADRO 1. CÓMO INFLUYE EL ASESINATO/DESAPARICIÓN DE LOS FAMILIARES EN EL PROYECTO DE VIDA DE LAS MUJERES ENTREVISTADAS}

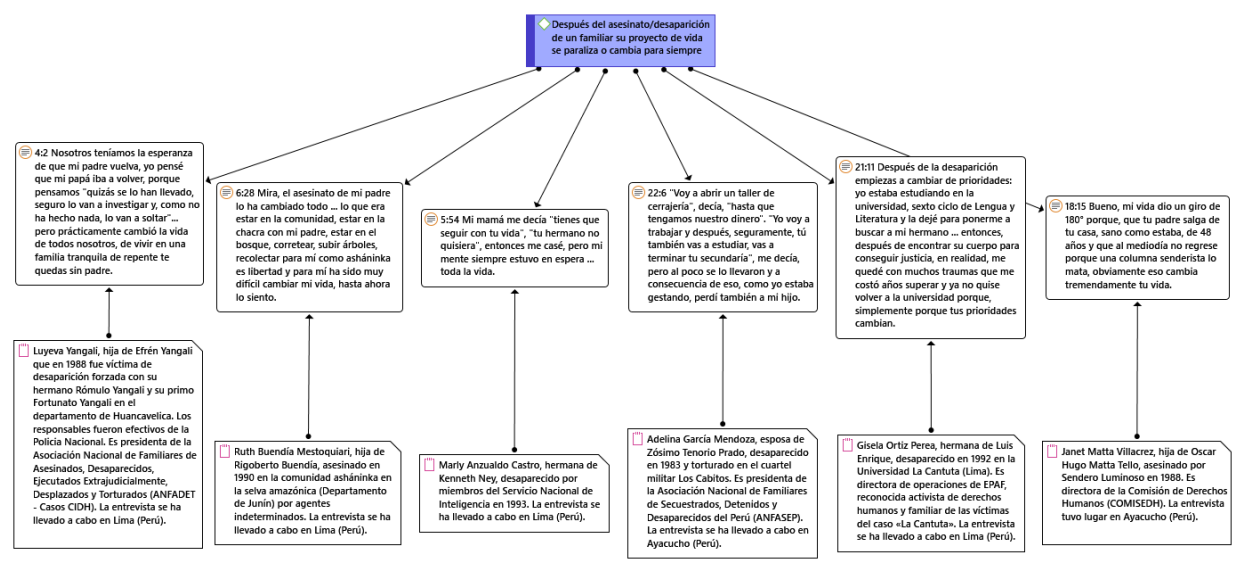

Fuente: Elaboración propia mediante el software Atlas.ti 8, a partir de las entrevistas cualitativas llevadas a cabo en Perú.

En muchas ocasiones, la única manera para poder ponerse a salvo era desplazarse del campo a la ciudad y, en ocasiones, nuevamente desde la ciudad al campo, tratando de fugarse continuamente ante el avance de un enemigo cambiante que hoy podría ser un grupo subversivo, el día siguiente las Fuerzas Armadas, entre otros (Cuadro 3). Para las mujeres, las pérdidas fueron múltiples, habiendo tenido que afrontar no solo la ausencia de un ser querido, sino también tener que abandonar sus casas y sus propiedades para huir, lidiar con el desarraigo cultural que conlleva el desplazamiento forzoso -fenómeno que ha afectado a más de 600.000 personas en todo el país- y la estigmatización social en el nuevo lugar de residencia. En ocasiones sus rasgos andinos o indígenas, el analfabetismo o el escaso conocimiento del castellano, los escasos recursos, el estigma de la violencia recibida las llevaron a tener que soportar la exclusión social, la discriminación y una culpabilización inmerecida, tanto en el lugar que dejaron atrás como en el nuevo lugar de acogida (Cuadro 3).

Sin embargo, a pesar de todos los sufrimientos padecidos, muchas mujeres peruanas durante el conflicto decidieron reaccionar con resiliencia frente a la adversidad, tratando de mejorar su situación personal mediante el trabajo y los estudios, a fin de asegurar un futuro mejor para ellas mismas y sus familias. Los desafíos no fueron pocos, en una sociedad tradicional, en la cual se asignaba a la mujer exclusivamente el papel de «madre» $\mathrm{O}$ «esposa», roles únicamente asociados al cuidado del hogar y a la crianza de los hijos (Cuadro 2).

Sin duda, uno de los mayores desafíos que la mujer peruana durante el conflicto y en el posconflicto ha afrontado es la búsqueda de sus familiares desaparecidos. Dicha labor de búsqueda las ha llevado a visitar hospitales, dependencias policiales, bases militares, cárceles e incluso morgues, exponiéndolas a ser objeto de nuevos delitos como violaciones sexuales, detenciones, torturas, amenazas. Demasiadas veces tuvieron que soportar la impunidad patente 


\section{CUADRO 2. EL ASESINATO/DESAPARICIÓN DE SU FAMILIAR ACARREA CONSECUENCIAS PSICOLÓGICAS ECONÓMICAS Y EN LA EDUCACIÓN DE TODA LA FAMILIA}

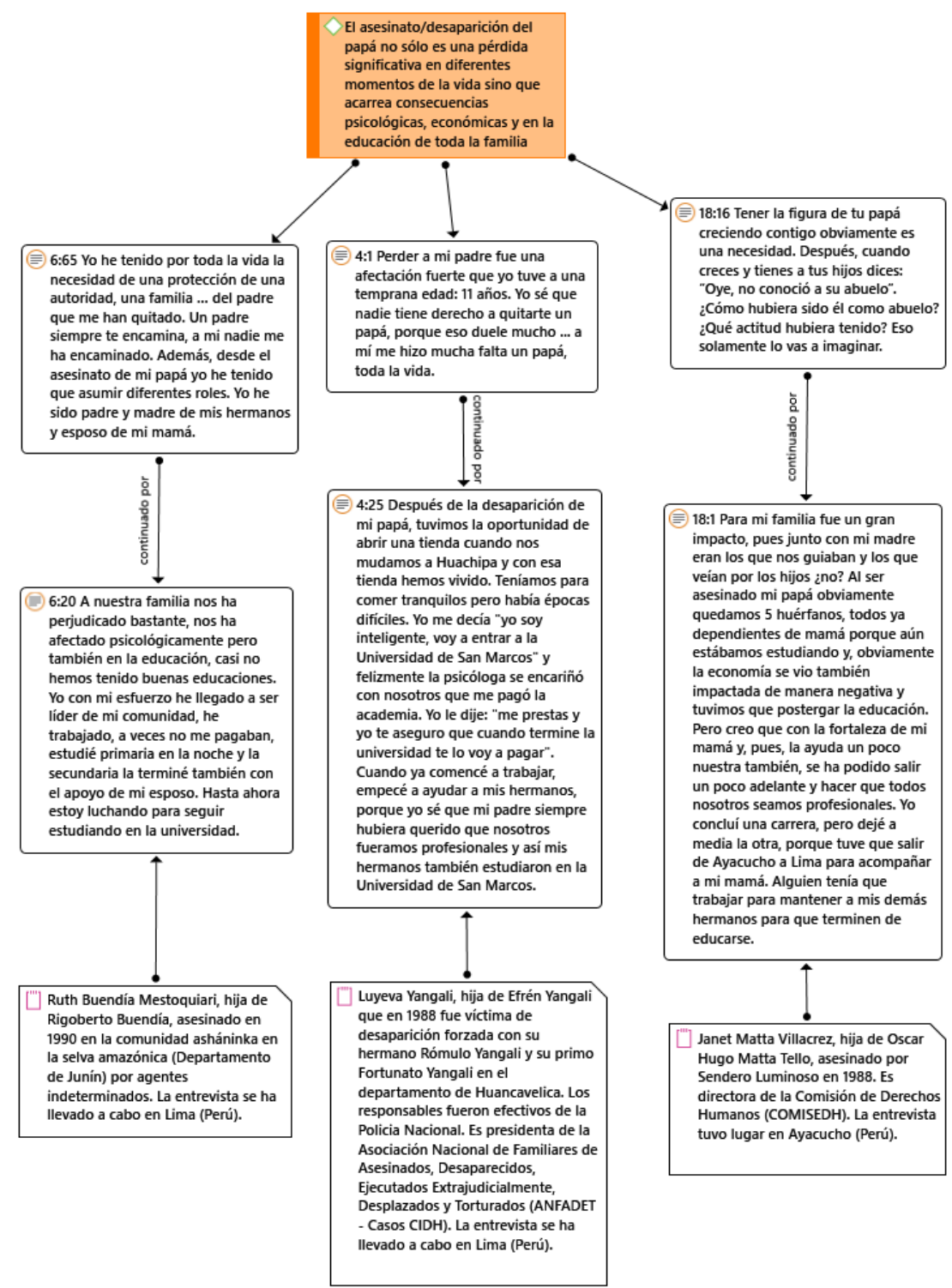

Fuente: Elaboración propia mediante el software Atlas.ti 8, a partir de las entrevistas cualitativas llevadas a cabo en Perú. 


\section{CUADRO 3. LA VIOLENCIA DE SENDERO LUMINOSO Y DE LOS AGENTES DEL ESTADO OBLIGA A MUCHAS MUJERES A DESPLAZARSE PARA PONERSE A SALVO}

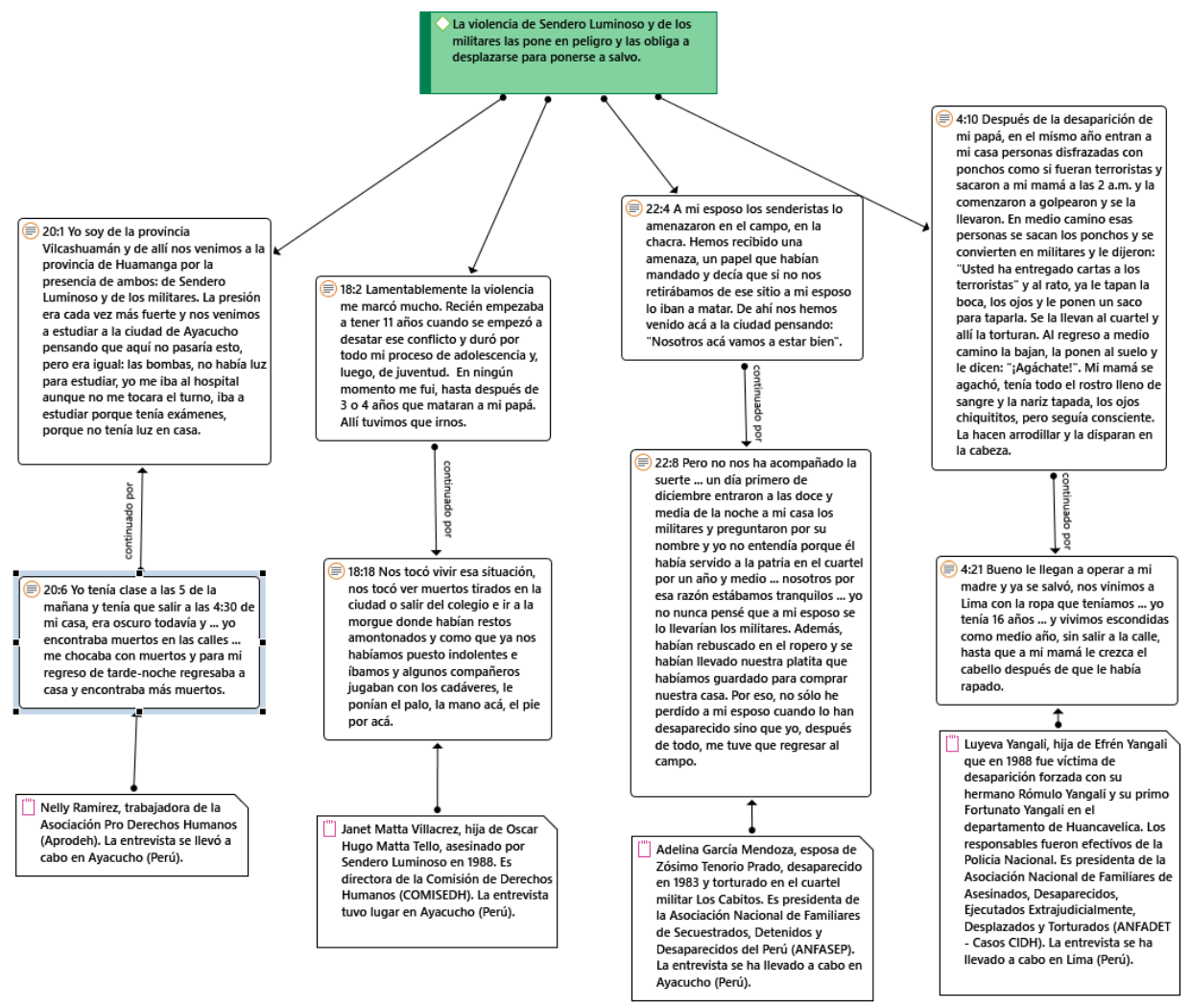

Fuente: Elaboración propia mediante el software Atlas.ti 8, a partir de las entrevistas cualitativas llevadas a cabo en Perú.

de la que gozaron los perpetradores, a menudo, agentes del Estado que les ocultaron la verdad y obstaculizaron la obtención de justicia (Ortiz Perea, 2017). En otros casos la búsqueda las llevó a conocer los hechos, descubriendo una verdad horrible, inhumana, indecente: para destruir las evidencias de las ejecuciones cometidas, los cadáveres de sus familiares fueron eliminados mediante mutilación, incineración de restos, arrojando los cuerpos en los ríos u otras zonas inaccesibles, sepultándolos en sitios de entierro o esparciendo las partes de los cuerpos en diferentes lugares para dificultar su identificación. Así lo testimonia Marly (Cuadro 4) (comunicación personal, 2018), cuyo hermano Kenneth Ney Anzualdo Castro fue detenido en 1993 y llevado, junto a su compañero Martín Javier Roca Casas, a los sótanos del edificio conocido 


\section{CUADRO 4. LA BÚSQUEDA DE LOS FAMILIARES DESAPARECIDOS, EN ALGUNOS CASOS, LLEVA A LAS MUJERES PERUANAS A DESCUBRIR UNA VERDAD INHUMANA Y ABERRANTE}

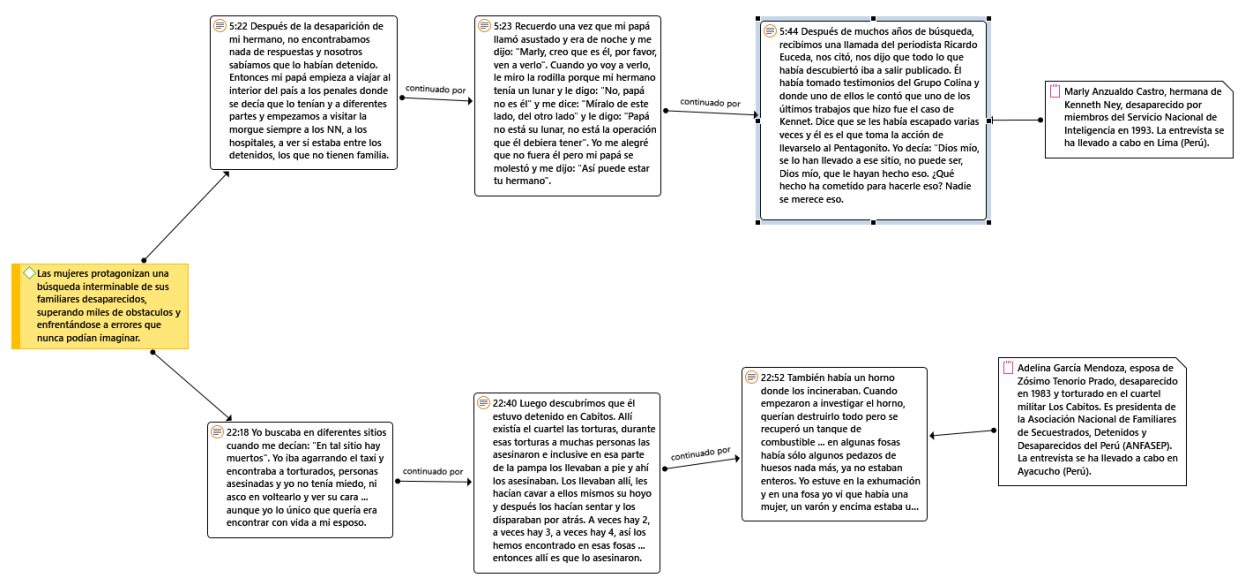

Fuente: Elaboración propia mediante el software Atlas.ti 8, a partir de las entrevistas cualitativas llevadas a cabo en Perú.

como el Pentagonito, en Lima, sede del Servicio de Inteligencia del Ejército (SIE), donde muchas de las personas desaparecidas fueron incineradas en hornos crematorios ${ }^{5}$.

Tales hechos fueron confirmados por la Corte Suprema peruana en 2017, la cual condenó a Vladimiro Montesinos Torres, Nicolás de Bari Hermoza Ríos, Jorge Enrique Nadal Paiva, miembros del Servicio de Inteligencia del Ejército peruano, como autores mediatos del delito de desaparición forzada.

Adelina García Mendoza (comunicación personal 2018) nos relata el caso de su esposo (Cuadro 4), Zósimo Tenorio Prado, desaparecido en 1983, torturado en el cuartel Militar «Domingo Ayarza», más conocido como «Los Cabitos», en Ayacucho. La Sala Penal Nacional de la Corte Suprema en 2017 dictó una sentencia histórica relativa a las violaciones de los derechos humanos realizadas en este cuartel, dejando probado que, en los años 80, centenares de personas fueron detenidas de forma arbitraria y sometidas a tortura con la finalidad de que confesasen su supuesta afiliación a SL, para ser finalmente ejecutadas extrajudicialmente, sepultadas en fosas comunes o finalmente incineradas en hornos crematorios (Reyes, 2017).

Estas historias son algunas de las millares que se han quedado en el olvido por décadas y que aún permanecen desconocidas; historias de mujeres que, además de haber sufrido la pérdida de un ser querido, fueron objeto de numerosas revictimizaciones (Guerrica Echevarría y Echeburúa Odriozola, 2006, p. 198), puesto que no solo padecieron el daño y la vulneración de sus derechos, sino que fueron humilladas, culpabilizadas por los mismos perpetradores;

5. Caso Anzualdo Castro vs. Perú (Corte Interamericana de Derechos Humanos, 1994). 
desatendidas y desprotegidas por los poderes públicos; marginadas, excluidas y estigmatizadas por el resto de la sociedad civil.

Sin embargo, a pesar de todo, ellas intentaron ayudarse mutuamente dando vida a un movimiento de derechos humanos que trató de afrontar distintas urgencias: en primer lugar, alentar el cese de la violencia subversiva, cuyo fin principal era destruir al Estado peruano; en segundo lugar, contrarrestar la progresiva erosión de las instituciones democráticas, cuyo auge fue el golpe de Estado del 5 de abril de 1992 y la consiguiente instauración del régimen autoritario de Alberto Fujimori; por último, recuperar a los familiares desaparecidos e impulsar políticas públicas a favor de los derechos a la verdad, a la justicia, a la memoria y a la reparación (CVR, 2003a, p. 295).

\section{CUADRO 5. LA BÚSQUEDA DE LOS FAMILIARES DESAPARECIDOS LLEVA A LAS MUJERES A ASOCIARSE Y A LUCHAR POR EL RESPETO DE SUS DERECHOS}

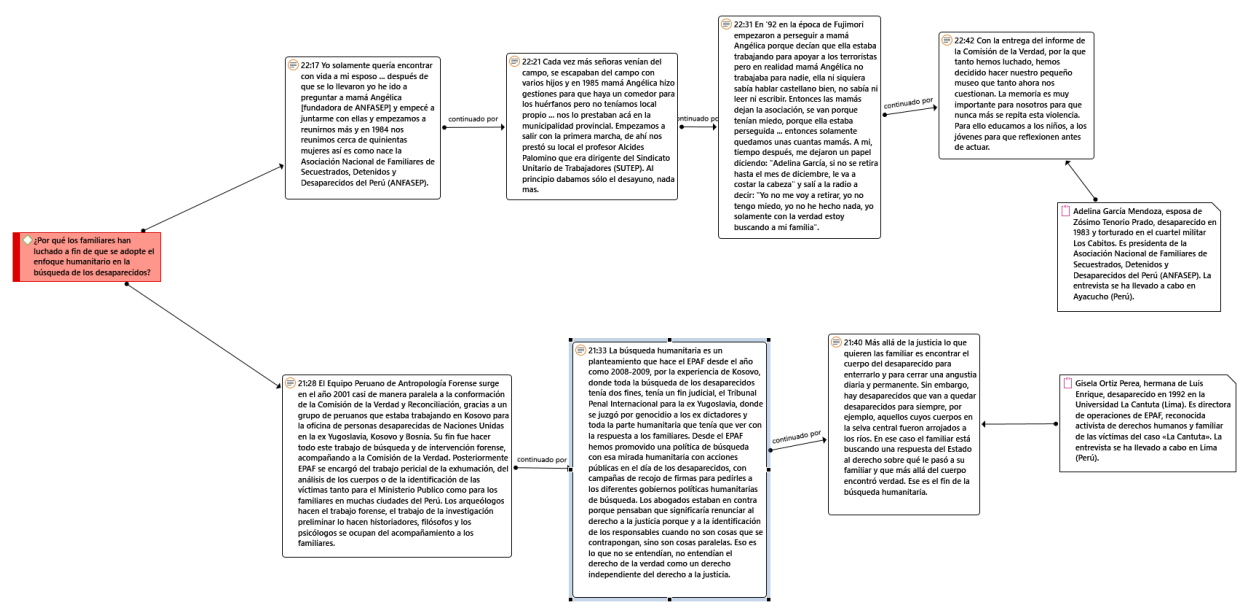

Fuente: Elaboración propia mediante el software Atlas.ti 8, a partir de las entrevistas cualitativas llevadas a cabo en Perú.

Las acciones del movimiento de derechos humanos contribuyeron a que en 2001 se instituyera la CVR, gracias a la cual por primera vez alrededor de 16.000 personas ofrecieron su testimonio, dando a conocer los horrores a los que fueron sujetas. El Informe de la CVR avaló muchas de las demandas del movimiento, recomendando, entre otras cuestiones, la adopción de políticas específicas en materia de reparación.

A la luz de las recomendaciones de la CVR, a partir del 2005 se puso en marcha una política de reparación con la Ley n. ${ }^{\circ} 28592$ (Aprobación del Plan Integral de Reparación a las Víctimas de la Violencia) y su reglamento de actuación aprobado en 2006. Gracias a tales instrumentos legislativos, se creó la Comisión Multisectorial de Alto Nivel (CMAN), encargada 
del seguimiento de las acciones y políticas del Estado en los ámbitos de la paz, la reparación colectiva y la reconciliación, como ente rector del sistema (Ulfe Young, 2013); el Consejo de Reparaciones (CR), encargado de la elaboración del Registro Único de Víctimas (RUV) y de la acreditación, identificación e individualización de las víctimas y diferentes programas de reparación (Lerner Febres, 2007).

Diez años después de ese primer paso en materia de reparación, gracias a la incansable lucha pacífica de los familiares, en 2016 se promulgó la Ley n. ${ }^{\circ}$ 30470, Ley de Búsqueda de personas desaparecidas durante el periodo de violencia 1980-2000, que tiene como finalidad la búsqueda, recuperación, análisis, identificación y restitución de los restos humanos de las personas desaparecidas. Asimismo, en 2018 con el decreto legislativo n. ${ }^{\circ} 1398$ se aprobó la creación por parte de la Dirección General de Búsqueda de Personas Desaparecidas (DGBPD), en el marco del Ministerio de Justicia y Derechos Humanos, de un banco de datos genéticos que permitirá contrastar el ADN de los familiares de las víctimas con los restos óseos hallados en las fosas (El Comercio, 2018).

La DGBPD, finalmente, adoptó el enfoque humanitario en la búsqueda de los desaparecidos, propuesto por el movimiento de derechos humanos y equipos de expertos, tal como testimonia Gisela Ortiz (comunicación personal, 2018), directora de Operaciones del Equipo Peruano de Antropología Forense (EPAF) en el Cuadro V. Tal enfoque tiene el objetivo prioritario de satisfacer el derecho a la verdad de los familiares y su necesidad de cerrar el duelo, intentando darles a conocer la verdad sobre lo ocurrido y, posiblemente, localizando, exhumando y entregándoles los restos de sus seres queridos, prescindiendo de si los culpables de este delito estén identificados, juzgados y condenados (EPAF y CNDDHH, 2009).

A pesar de los pasos que en estos 20 años de posconflicto se han dado hacia la reparación de las víctimas del CAI en Perú, los informes de la Defensoría del Pueblo, que monitorean la implementación de las recomendaciones de la CVR (Defensoría del Pueblo, 2008), reportan graves insuficiencias en las medidas aprobadas y una escasa implementación de las mismas, por la presencia de obstáculos administrativos que, a menudo, no solo impiden esclarecer los hechos y poner fin a la impunidad de los responsables, sino que siguen causando nuevas y severas revictimizaciones a los familiares (Defensoría del Pueblo, 2013).

Para paliar tales carencias, una miríada de asociaciones y ONG -algunas de ellas muy reconocidas como la Asociación Pro Derechos Humanos (APRODEH); la Comisión de Derechos Humanos (COMISEDH); la Asociación Nacional de Familiares de Secuestrados, Detenidos y Desaparecidos del Perú (ANFASEP); la Coordinadora General de Derechos Humanos, entre otras- nacidas durante y después del conflicto, por una parte, han suplido directamente la atención que el Estado debió otorgarles a los afectados ofreciéndoles asistencia legal, judicialización de los casos, atención a los desplazados, apoyo logístico y acompañamiento psicosocial en las restituciones o entrega de restos, transmisión del legado de la memoria a las nuevas generaciones, entre otras actividades (Crisóstomo, 2019). Por la otra, han sido un vector de transmisión de las demandas y necesidades de los afectados a las instituciones públicas a fin de que, en algún momento, puedan cumplir con su deber de garantizarles el derecho a la verdad, a la justicia, a la memoria y a la reparación. 


\section{CONCLUSIONES}

Como sostiene Calbet (2018), la violencia sexual contra las mujeres durante los conflictos armados, en buena medida, puede ser utilizada como arma de guerra, como forma de control de la sociedad o humillación simbólica del enemigo. Tal como hemos comprobado, el CAI peruano no fue una excepción, ya que la violencia sexual fue ejercida de forma masiva con esos mismos fines, tanto por los agentes del Estado como por los grupos subversivos (COMISEDH, 2003). Es más, la violencia sexual contra las mujeres en Perú no parece haber surgido durante el conflicto, sino haber sido exacerbada por él: en el CAI una tríplice discriminación llegó a su auge, causando la violencia más despiadada, especialmente en contra de las mujeres más vulnerables: indígenas o campesinas de la sierra y la selva del Perú (Boesten y Fischer, 2012, p. 3). En este sentido, la violencia sexual precedió y supervivió al conflicto, no pudiéndola considerar solo como una estrategia de guerra, porque fue normalizada y tolerada también en tiempos de paz.

Respondiendo a la primera pregunta de investigación sobre el impacto de la violencia del CAI en las mujeres peruanas, es importante resaltar que, además de la violencia física padecida, las víctimas de violación sexual sufrieron graves traumas psicológicos, generados por la humillación que la misma violación supone y el deshonor que este delito, si se releva, haya podido causarles en el marco de su comunidad de pertenencia. En palabras de Ríos y Brocate (2017, p. 84), de hecho, la violación de la mujer constituye una humillación tanto para el hombre como para la comunidad. En ese contexto, la mujer es considerada como propiedad del hombre y del conjunto colectivo (la comunidad): violar su cuerpo significa violentar a la comunidad. Esta concepción patriarcal de la sociedad y su consiguiente asignación rígida del rol hombre-mujer conlleva, sin duda, la revictimización de la misma mujer, la cual ante una violación sexual es repudiada por sus familias y marginada por el resto de la sociedad.

En cuanto al impacto de las desapariciones forzadas, las ejecuciones extrajudiciales y los asesinatos, en muchas ocasiones, para las mujeres las pérdidas fueron múltiples, habiendo tenido que afrontar no solo la ausencia de un ser querido, sino también asumir solas la carga familiar, lidiar con el desplazamiento forzoso y la estigmatización social en el nuevo lugar de residencia.

Respondiendo a nuestra segunda pregunta de investigación en torno al papel de las mujeres en el conflicto y posconflicto en Perú, gracias al análisis de las entrevistas, se puede afirmar que, a pesar de todas las injusticias sufridas, muchas de ellas han luchado contra la impunidad, siendo protagonistas de una interminable y desgarradora búsqueda de sus familiares y allegados, víctimas de la desaparición forzada y de las ejecuciones extrajudiciales. Podríamos, por tanto, concluir que muchas mujeres peruanas han sido y son un ejemplo cívico, gracias a la creación de un movimiento pacífico en defensa de los derechos humanos que, por un lado, ha intentado colmar la desatención del Estado hacia los afectados y, por otro, ha luchado y sigue luchando por una mayor efectividad del derecho a la verdad, a la justicia, a la memoria y a la reparación.

Los resultados parciales obtenidos en esta investigación preliminar, con toda seguridad, constituyen un punto de partida para próximos trabajos que exploren cómo promover el diseño de políticas públicas a fin de reducir las discriminaciones del posconflicto peruano, sobre todo las ejercidas a daño de sujetos vulnerables como las mujeres, víctimas de la violencia y, en su mayoría, pertenecientes a comunidades indígenas y campesinas. 


\section{REFERENCIAS}

\section{V1.1. Fuentes primarias}

Entrevista a Adelina García Mendoza (2018). Esposa de Zósimo Tenorio Prado, desaparecido en 1983 y torturado en el cuartel militar Los Cabitos y presidenta de la Asociación Nacional de Familiares de Secuestrados, Detenidos y Desaparecidos del Perú (ANFASEP). Ayacucho, Perú.

Entrevista a Gisela Ortiz Perea (2018). Hermana de Luis Enrique, desaparecido en 1992 en la Universidad La Cantuta (Lima) y directora de Operaciones de EPAF, reconocida activista de derechos humanos y familiar de las víctimas del caso «La Cantuta». Lima, Perú.

Entrevista a Janet Matta Villacrez (2018). Hija de Oscar Hugo Matta Tello, asesinado por Sendero Luminoso en 1988 y directora de la Comisión de Derechos Humanos (COMISEDH). Ayacucho, Perú.

Entrevista a Marly Anzualdo Castro (2018). Hermana de Kenneth Ney, víctima de desaparición forzada, cuyos responsables fueron miembros del Servicio Nacional de Inteligencia en 1993. Lima, Perú.

Entrevista a Nelly Ramírez (2018). Trabajadora de la Asociación Pro Derechos Humanos (APRODEH). Ayacucho, Perú.

Entrevista a Ruth Buendía Mestoquiari (2018). Hija de Rigoberto Buendía, asesinado en 1990 en la comunidad asháninka en la selva amazónica (departamento de Junín) por agentes indeterminados. Lima, Perú.

Entrevista a Luyeva Yangali (2018). Hija de Efrén Yangali que, en 1988, víctima de desaparición forzada en el departamento de Huancavelica junto con su hermano Rómulo Yangali y su primo Fortunato Yangali, cuya responsabilidad fue atribuida a efectivos de la Policía Nacional. Es presidenta de la Asociación Nacional de Familiares de Asesinados, Desaparecidos, Ejecutados Extrajudicialmente, Desplazados y Torturados (ANFADET - Casos CIDH). Lima, Perú.

\section{V1.2. Fuentes secundarias}

Aguilar, Y. y Fulchiron, A. (2005). El carácter sexual de la violencia contra las mujeres. En M. A. Garavito, P. Us, Y. Aguilar, A. Fulchiron y R. Kepfer. Las violencias en Guatemala. Algunas perspectivas (pp. 149-246). FLACSO - UNESCO.

Beristain, M., Dona, G., Paez, D., Pérez, P., y Fernández, I. (1999). Reconstruir el tejido social. Un enfoque crítico de la ayuda humanitaria. Icaria editorial / Antrazyt.

Boesten, J. y Fisher, M. (2012). Sexual Violence and Justice in Postconflict Peru. Special Report. United States Institute of Peace. https://www.usip.org/sites/default/files/SR310.pdf

Boutron, C. (2014). De las experiencias invisibles: las mujeres en los comités de Autodefensa durante el conflicto armado en Perú. Colombia Internacional, (80), 234-251. https://doi.org/10.7440/colombiaint80.2014.08

Calbet, N. (2018). La violencia sexual en Colombia, mujeres víctimas y constructoras de paz. Institut de Drets Humans de Catalunya.

COMISEDH. (2003). Violaciones sexuales a mujeres durante la violencia política en el Perú. COMISEDH.

Corbetta, P. (2003). Metodologia y técnicas de investigación social. McGrawhill.

Corbin J. y Strauss, A. (2008), Basics of Qualitative Research. Sage Publication: Thousand Oaks.

Corte Interamericana de Derechos Humanos. (1993). Loayza Tamayo Vs. Perú. Corte Interamericana de Derechos Humanos. https://www.corteidh.or.cr/CF/jurisprudencia2/ficha_tecnica.cfm?nId_Ficha $=311$

Corte Interamericana de Derechos Humanos. (1994). Anzualdo Castro Vs. Perú. Corte Interamericana de Derechos Humanos. https://www.corteidh.or.cr/CF/jurisprudencia2/ficha_tecnica.cfm?nId_Ficha=279 
Corte Penal Internacional. (1999). Estatuto de Roma de la Corte Penal Internacional. Corte Penal Internacional. https://www.un.org/spanish/law/icc/statute/spanish/rome_statute(s).pdf

Crisóstomo, M. (2011, 1 de diciembre). La violencia sexual durante el CAI peruano. Un caso de las mujeres rurales del Perú. [Conferencia] IV Seminario Internacional de Políticas de Memoria. Ampliación de campo de los derechos humanos, memorias y perspectivas, Buenos Aires, Argentina. http://conti.derhuman.jus.gov.ar/2011/10/mesa_9/crisostomo_mesa_9.pdf

Crisóstomo, M. (2015). Mujeres y fuerzas armadas en un contexto de violencia politica. Los casos de Manta y Vilca en Huancavelica. Instituto de Estudios Peruanos.

Crisóstomo, M. (2019). Memories between Eras. ANFASEP's leaders and after Peru's Internal Armed Conflict. Latin American Perspectives, 46(5), 128-142. https://doi.org/10.1177/0094582X19856901

CVR. (2003a). Informe Final de la Comisión de la Verdady la Reconciliación. «El movimiento de derechos humanos», Tomo III, Cap. 3.1. Comisión de la Verdad y la Reconciliación. https://www.cverdad.org.pe/ifinal/

CVR. (2003b). Informe Final de la Comisión de la Verdady la Reconciliación. «La tortura y los tratos crueles, inhumanos o degradantes». Tomo VI, Sección Cuarta, Capítulo 1.4. Comisión de la Verdad y la Reconciliación. https://www.cverdad.org.pe/ifinal/

CVR. (2003c). Informe Final de la Comisión de la Verdady la Reconciliación. «La violencia en las regiones». Tomo IV, Sección Tercera, Capítulo 1. Comisión de la Verdad y la Reconciliación. https:/ /www.cverdad.org. $\mathrm{pe} /$ ifinal/

CVR. (2003d). Informe Final de la Comisión de la Verdad y la Reconciliación. «Violencia sexual contra la mujen». Tomo VI, Sección Cuarta, Capítulo 1.5. Comisión de la Verdad y la Reconciliación. https://www. cverdad.org.pe/ifinal/

CVR. (2003e). Informe Final de la Comisión de la Verdad y la Reconciliación. «Violencia y desigualdad de género». Tomo VIII, Segunda Parte, Capítulo 2.1. Comisión de la Verdad y la Reconciliación. https://www. cverdad.org.pe/ifinal/

CVR. (2003f). Informe Final de la Comisión de la Verdad y Reconciliación. Compendio estadístico, Anexo 3. Comisión de la Verdad y la Reconciliación. https://www.cverdad.org. pe/ifinal/

Defensoría del Pueblo. (2000). La desaparición forzada de personas en el Perú. Defensoría del Pueblo. http://www. derechos.org/nizkor/peru/libros/desap/

Defensoría del Pueblo. (2004). Violencia Politica en el Perú: 1980-1996. Un acercamiento desde la perspectiva de género. Defensoría del Pueblo. https://biblioteca.cejamericas.org/bitstream/handle/2015/3718/per-defgenero.pdf?sequence $=1$ \&is Allowed $=\mathrm{y}$

Defensoría del Pueblo. (2008). A cinco años de los procesos de reparación y justicia en el Perú. Balance y desafíos de una tarea pendiente. Defensoría del Pueblo. https://biblioteca.corteidh.or.cr/documento/56483

Defensoría del Pueblo. (2013). A diez años de verdad, justicia y reparación. Avances, retrocesos y desafios de un proceso inconcluso. Defensoría del Pueblo. https://www.defensoria.gob.pe/modules/Downloads/informes/defensoriales/INFORME-DEFENSORIAL-162.pdf

Degregori, C. I. (2014). Heridas abiertas, derechos esquivos. Derechos humanos, memoria y Comisión de la Verdad y Reconciliación. IEP.

Díaz, E. S. (2016). Los papeles de la mujer en los grupos insurgentes-terroristas iberoamericanos: entre víctimas y victimizadoras (Documento de Análisis No. 52). Instituto de Estudios Estratégicos. https://www.ieee.es/Galerias/ fichero/docs_analisis/2016/DIEEEA52-2016_Mujer_GruposTerroristas_iberoamerica_ESRD.pdf

El Comercio. (2018, 1 de septiembre). Aprueban decreto legislativo para la creación de banco de datos genéticos. El Comercio. https://www.google.com/search?client=safari\&rls=en\&q=Aprueban + decreto + legislativo + para + la + creaci $\% \mathrm{C} 3 \% \mathrm{~B} 3 \mathrm{n}+\mathrm{de}+$ banco + de + datos + gen $\% \mathrm{C} 3 \% \mathrm{~A} 9 \mathrm{ticos} . \& \mathrm{ie}=\mathrm{UTF}-8 \&$ oe $=$ UTF-8

El Comercio. (2021, 12 de enero). Alberto Fujimori y las claves de la denuncia por el Caso de Esterilizaciones Forzadas. El Comercio. https://elcomercio.pe/politica/justicia/alberto-fujimori- 
y-las-claves-de-la-denuncia-por-el-caso-de-esterilizaciones-forzadas-keiko-fujimori-poder-judicial-noticia/

EPAF y CNDDHH. (2009). Desaparición Forzada en el Perú: el aporte de la investigación antropológica forense en la obtención de la evidencia probatoria y la construcción de un paraguas bumanitario. CNDDHH - EPAF.

Guerrica Echevarría, C. y Echeburúa Odriozola, E. (2006). Especial consideración de algunos ámbitos de victimación. En E. Echeburúa Odriozola, E. Baca Baldomero y J. M. Tamarit Sumalla (Coords.), Manual de víctimología. Tirant lo Blanch.

Jara Gómez, A. M. (2013). Mujer y guerra en los Balcanes. Kosovo: entre los derechos perdidos y la identidad pendiente. Dykinson.

La Vanguardia. (2021, 2 de marzo). Perú juzga a Alberto Fujimori por la esterilización forzosa de mujeres indígenas. La Vanguardia.

Lerner Febres, S. (2007). Justicia y reparación para las víctimas de la violencia política. Revista Páginas, XXXII(207), 52-58.

Lirola, I. y Martin, M. M. (2016). Crímenes internacionales de violencia sexual y conflictos armados. Thomson Reuters-Aranzadi.

LUM. (2018, 24 de abril). Presentan lista del Registro Nacional de Personas Desaparecidas y Sitios de Entierro (Renade). Lugar de la memoria, la tolerância y la inclusión social. https://lum.cultura.pe/noticias/ presentan-lista-del-registro-nacional-de-personas-desaparecidas-y-sitios-de-entierro-renade

Mackenzie, M. (2010). Securitizing Sex? Towards a theory of the utility of wartime sexual violence. International Feminist Journal of Politics, 12(2), 202-221. https://doi.org/10.1080/14616741003665250

Moreyra, M. (2007). Conflictos armados y violencia sexual contra las mujeres. Del Puerto.

ONU. (2015). Conflict-related sexual violence, Report of the Secretary-General. United Nations. http://www.securitycouncilreport.org/atf/cf/\%7B65BFCF9B-6D27-4E9C-8CD3-CF6E4FF96FF9\%7D/s_2015_203. pdf

Ortiz Perea, G. (2017). Hasta encontrarlos. La identidad como derecho: retos y lecciones en la búsqueda de los desaparecidos en el Perú. Memoria, 23, 8-17. https://idehpucp.pucp.edu.pe/wp-content/ uploads/2017/08/hasta-encontrarlos_gortiz.pdf

Patton, M. Q. (1990). Qualitative evaluation and research methods. Sage Publication.

Reyes, V. (2017, 21 de agosto). Justicia para las víctimas de Los Cabitos, un análisis del fallo. Instituto de Democracia y Derechos Humanos de la Pontificia Universidad Católica del Perú. https://idehpucp.pucp.edu.pe/ notas-informativas/justicia-las-victimas-los-cabitos-analisis-del-fallo/

Ríos, J. y Brocate, R. (2017). Violencia sexual como crimen de lesa humanidad: los casos de Guatemala y Perú. Revista CIDOB d'Afers Internacionals, 117, 79-99. https// doi.org/10.24241/rcai.2017.117.3.79

Ruta Pacífica de las Mujeres. (2013). La verdad de las mujeres. Victimas del conflicto armado en Colombia. Ruta Pacífica de las Mujeres. https://www.aecid.es/Centro-Documentacion/Documentos/Publicaciones $\% 20$ coeditadas $\% 20$ por $\% 20$ AECID $/$ La $\% 20$ verdad $\% 20$ de $\% 201$ la $\% 20$ mujeres $\% 20($ Tomo\%201).pdf

Ulfe Young, M. E. (2013). ¿Y después de la violencia qué queda? Victimas, ciudadanos y reparaciones en el contexto postCVR en el Perú. CLACSO.

Varona, G. (2015). Guía general de buenas prácticas en el trato con víctimas del terrorismo que evite la victimización secundaria. Gobierno Vasco, Secretaría General para la Paz y la Convivencia. https://www.euskadi.eus/contenidos/proyecto/victimas_proyecto006/es_def/adjuntos/Guia_general_buenas_practicas.pdf

Villellas, A., Urrutia, P., Royo, J. M. y Villellas, M. (2016). Violencia sexual en conflictos armados. Quaderns de Construcción de Pau, 27, 1-16. 
